\title{
Microstructure and Properties of Polymer Composites
}

\author{
Jan Hajsman ${ }^{1}$, Stepan Jenicek ${ }^{1}$, Ludmila Kucerova ${ }^{1}$, David Rieger ${ }^{2}$ \\ ${ }^{1}$ Regional Institute of Technology, Faculty of Mechanica Engineering, University of West Bohemia, Univerzitní 8 \\ 30614 Plzeň. Czech Republic. E-mail: janh@rti.zcu.cz, jeniceks@rti.zcu.cz, skal@rti.zcu.cz \\ ${ }^{2}$ New Technologies - Research Centre, University of West Bohemia, Univerzitní 830614 Plzeň. Czech Republic. E-mail: \\ davidpj@ntc.zcu.cz
}

This work aimed to characterise microstructure and mechanical properties of polymer composite samples. The main task was to adapt the well-known techniques of metallography (i.e. sample preparation and microscopic examination) to documentation of multi-component polymer materials and to optimize the methods of light and electron microscopy for this particular purpose. There were several issues (e.g. low melting point, absence of electrical conductivity), which made the process different from metal samples preparation and observation and which needed to be addressed. Various mounting resins were tested for the samples to find the suitable one, then the process of grinding and polishing was optimized and finally the microstructure was documented using light and scanning electron microscopy (SEM). Samples in the undeformed state were examined as well as the samples subjected to tensile test at different temperatures. Prior to the microscopic observations the material was analysed using methods of thermal analysis (TGA, DSC) and infrared spectroscopy (FT-IR). The tensile tests were employed not only to determine the mechanical properties but also to obtain deformed samples for further microscopic observation.

Keywords: polymer composites; microscopy; metallography; thermal analysis, tensile test

\section{Introduction}

Composite material consists of at least two components or phases which are combined in a specific way to reach unique mechanical, physical and chemical properties. There are two main types of components: matrix and the reinforcing phase. In case of the polymer composites both of the main components are made of polymer material (i.e. organic compound). The matrix defines the shape of the product, absorbs the impact and protects the reinforcing phase. It is made either of thermoplastic or thermoset polymers. The most used thermosets are for example epoxies, unsaturated polyesters, melamine or phenol-formaldehyde resins [1]. They are usually supplied in the liquid state and they cure by a chemical reaction during the manufacturing. Thanks to their initial liquid state the thermosets are easier to process as they perfectly fill all the space between the reinforcing phase elements. On the other hand thermoplastic materials have to be melted for the purposes of processing. High viscosity of thermoplastics makes the manufacturing more energy-intensive. Some of the most common thermoplastics in the composite manufacturing are polyetheretherketon (PEEK), polyphenylsulfide (PPS), polyamide-imides (PAI), polyimides (PI) and polysulfones (PSUL) [2].

The reinforcing phase is usually constituted by particles or fibers. The synthetic fibers are well known by their commercial names such as Kevlar (aramid fiber), Spectra (polyethylen), Vectran (polyester) or Zylon (poly(p-fenylen-benzobisoxazol)) [2-3]. To reinforce polymer matrices, only plant fibers based on cellulose are suitable for all natural fibers. These include cannabis, sisal, jute, ramie and cotton. Composites with natural fibers are often used where there is no strong need for strength and their function is more aesthetic [4].
In addition to the properties of the matrix and the secondary phase, the properties of the composite are significantly influenced by the physical and chemical nature of the phase interface between the matrix and the dispersed phase. The integrity of the phase interface affects the coherence between the reinforcement and the matrix, and hence the mechanical properties of the composite. There is a number of chemical compounds and technological processes to achieve the desired adhesive strength between the reinforcement and the matrix [5].

Polymer composites represent a group of materials whose importance and range of utilization is growing steadily. There is a strong tendency to replace conventional materials with composites in applications where the operation conditions allow it. Their advantages are above all low weight, greater shape variability, good strength properties, chemical resistance, etc. With the increase in production volume and the number of new types of polymer composites, grows also the necessity of developing suitable testing procedures including the methods of microscopy.

\section{Methods}

Since the chemical composition of the experimental material was unknown, the methods of thermogravimetric analysis (TGA), differential scanning calorimetry (DSC) and infrared spectroscopy (FTIR) were emloyed for the initial identification. The material used in this study is a composite consisting of a flexible plastic sheet of around $1 \mathrm{~mm}$ thickness and nonwoven fabric which covers one side of the sheet. It is an intermediate product designed to speed up and facilitate the moulding procedures in automotive industry.

Determination of the polymer type of the flexible sheet was performed using thermogravimetric analyser TA Q500 with nitrogen inert atmosphere. The initial 
weight of the sample was $13.587 \mathrm{mg}$. The experiment was performed in temperature range from 30 to $500^{\circ} \mathrm{C}$, which is a range commonly used for evaluation of polymers. The temperature gradient was set to $10^{\circ} \mathrm{C} / \mathrm{min}$.

For comparison, the material of the sheet was further tested with differential scanning calorimetry using instrument TA Q200. The experiment was performed within a temperature range $-50^{\circ} \mathrm{C}$ to $350^{\circ} \mathrm{C}$ in a power-compensated mode, i.e. power supply performance was kept constant both for the sample and the reference. The results of thermal analysis were evaluated by comparison with material database.

Fourier-transform infrared spectroscopy (FTIR) was employed to identify the material of the non-woven fabric fibers and to confirm the results of thermal analysis. Since the sample preparation procedure for transmission technique would be very difficult, the attenuated total reflectance (ATR) method was chosen instead. The spectrum obtained with this method is analogous to regular transmission infrared spectrum with certain differences in intensity of reflected radiation. Since the penetration depth of infrared radiation depends on the wavelength, the measured intensity is lower for shorter wavelengths compared to transmission spectrum. The experiment was carried out using IR spectrometer NICOLET iS5. Both samples (i.e. the sheet and the fibres ) were scanned 32 times in order to reduce the noise in the data. Spectral resolution (i.e. the minimum distance between two peaks ) was set to $4 \mathrm{~cm}^{-1}$.

Tensile tests were carried out according to EN ISO 527-4 using the device Zwick Roel Z250 equipped with high temperature furnace. Standardized samples (Fig. 1) were tested at temperatures 20, 40, 60, 80, 100, 120, 140 and $160^{\circ} \mathrm{C}$. The samples were prapared by waterjet cutting.

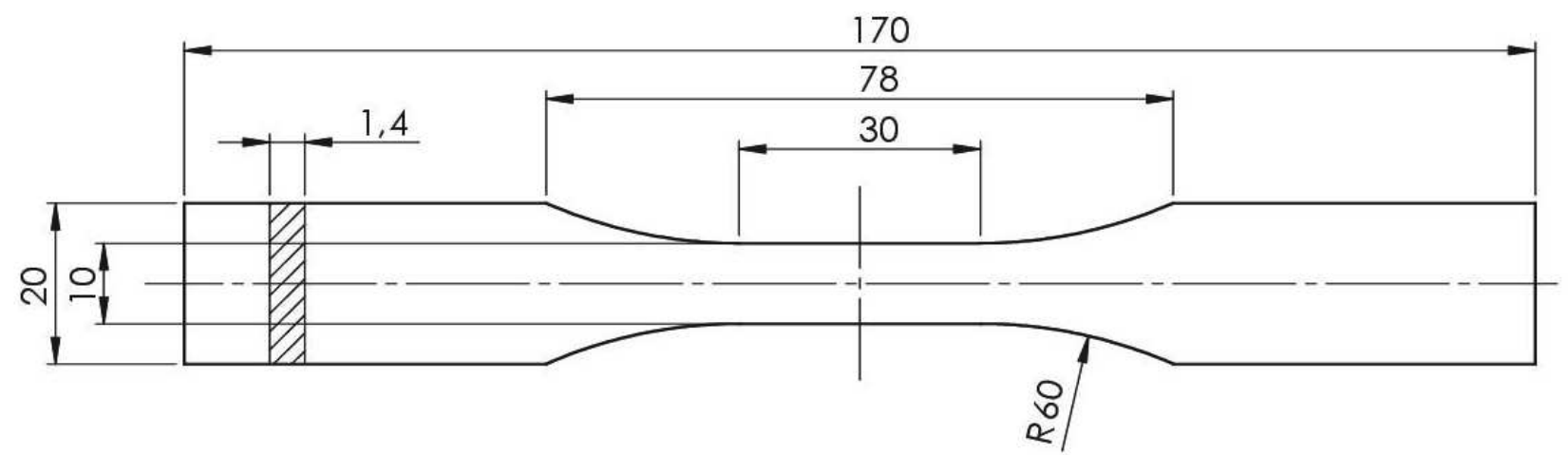

Fig. 1 Tensile specimen type $1 B$ according to EN ISO 527-4

After clamping the specimen into the jaws of the testing machine, the sample should be loaded with a preloading force to induce the stress $\sigma_{0}$ prescribed by EN ISO 527-4:

- For Young's modulus measurement: $\sigma_{0} \leqq \frac{\mathrm{E}}{2000}$

- For ultimate tensile strength measurement: $\sigma_{0} \leqq \frac{\sigma_{\mathrm{m}}}{100}$

For purposes of this experiment, the preloading force was set to induce stress $\sigma_{0}=0.1 \mathrm{MPa}$ for both measurements. The samples were loaded with dispalcement rate 2 $\mathrm{mm} / \mathrm{min}$ according to EN ISO 527-4. Three samples were tested at each tempereture from $20^{\circ} \mathrm{C}$ to $80^{\circ} \mathrm{C}$. At higher temperatures, where cracking doesn't appear any more due to increasing ductility of the polymer, the number of the saples was reduced to two. In case when the saple exhibits no breakage the ultimate tensile strenght is defined according to EN ISO 527-4 as the strees in the sample when the first local maximum of the stress-strain curve appear.

To observe the microstructure using light microscope Olympus BX61, samples with the size of 10x10 mm were cut. Since the melting point of the sheet is quite low $\left(160^{\circ} \mathrm{C}\right)$, there is a need to use cold mounting resin for the sample preparation, which makes the process more timeconsuming. Two mounting resins were tested: acrylic resin and epoxy resin. The samples of deformed tensile specimens were prepared in the same manner. The samples for fracture profile observation were grinded perpendicularly to the fracture surface. For fracture surface observation unmounted samples were used. At elevated temperatures $\left(80^{\circ} \mathrm{C}\right.$ and more $)$, the ductility of the material increased significantly and the fracture didn't appear any more. The samples were in this case taken from the middle of the deformed part to observe the deformation behaviour temperature dependence.

While there is no significant difficulty in observing polymer samples through a light microscope, electron microscopy brings several problems. Conventional scanning electron microscopy provides a good image only for electrically conductive samples. In the case of non-conducting samples, the accumulation of the negative charge occurs at the points of impact of the electron beam, resulting in deterioration in the quality of the resulting image. In order to suppress this phenomenon, the surface of samples is usually coated with a conductive layer, (i. e. metal or carbon thin film). If the sample surface is very rough, it is difficult to create a perfectly consistent layer that covers all the area and ensures conducting of the charge away from the sample. Applying such a layer can hide some fine details of the original surface, since the electron beam scans only this layer and not the sample itself. If the chemical composition is to be investigated, the feasibility of the measurement will depend on the primary electron beam energy and on the thickness of the conductive layer [6-8]. Another possibility to observe 
non-conductive preparations by scanning electron microscopy is using a low vacuum in the specimen chamber $\left(10^{-1}-10^{2} \mathrm{~Pa}\right)$, while the optical system is separated from the chamber by vacuum membrane. The atmosphere around the specimen becomes highly conductive at this pressure due to electron ionization. In this way, the charge generated on the surface of the sample is compensated by the surrounding atmosphere ions. There are also other methods of observing non-conductive specimens including a surface discharging with ion beam, an overlapping sample with a metal foil with a small aperture, X-ray irradiation, or the use of low energy electron beam. The disadvantage of examining polymers by electron microscopy is the fact that these materials may be susceptible to damage by the electron beam [6]. For purposes of this study the low-vacuum option was implemeneted using Zeiss EVO 25 scanning electron microscope with $\mathrm{LaB}_{6}$ cathode.

\section{Results and discussion}

The results of the thermal analysis are expressed with the temperature-dependent curves, Fig. 2 and 3.

The TGA curve (Fig. 2) represents the decrease of the sheet sample weight with rising temperature. The first measurable weight decrease was recorded around $230^{\circ} \mathrm{C}$. Rapid weight loss was observed between temperatures $400^{\circ} \mathrm{C}$ and $480^{\circ} \mathrm{C}$. The final weight of the sample is around $20 \%$ of the initial weight.

The resulting DSC curve (Fig. 3) represents the differences between heat flow of the sheet sample and the reference sample. This difference is correlated to the sample weight. The same experiment was carried out twice (continuous and dashed line in Fig. 3). The initial decreasing trend of the curves represents endothermic proces which becomes very intensive at temperatures over $100^{\circ} \mathrm{C}$. The local minimum point of the DSC curve (melting point) was measured at $160^{\circ} \mathrm{C}$. The glass transition temperature was not detected in this particular temperature range.

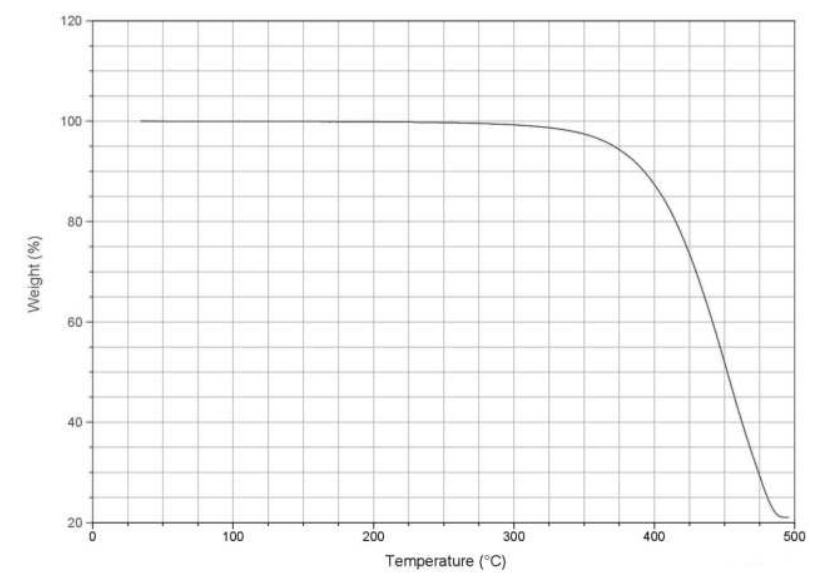

Fig. 2 TGA curve, sheet sample

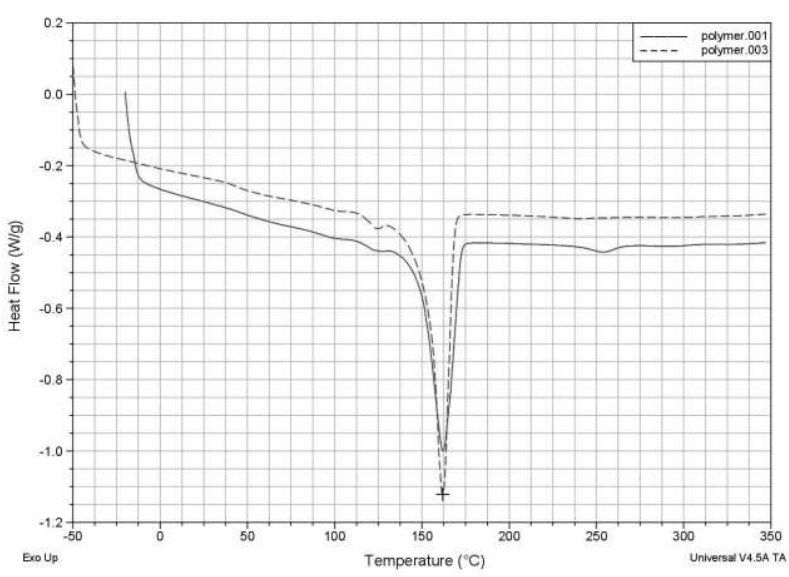

Fig. 3 DSC curves, sheet samples

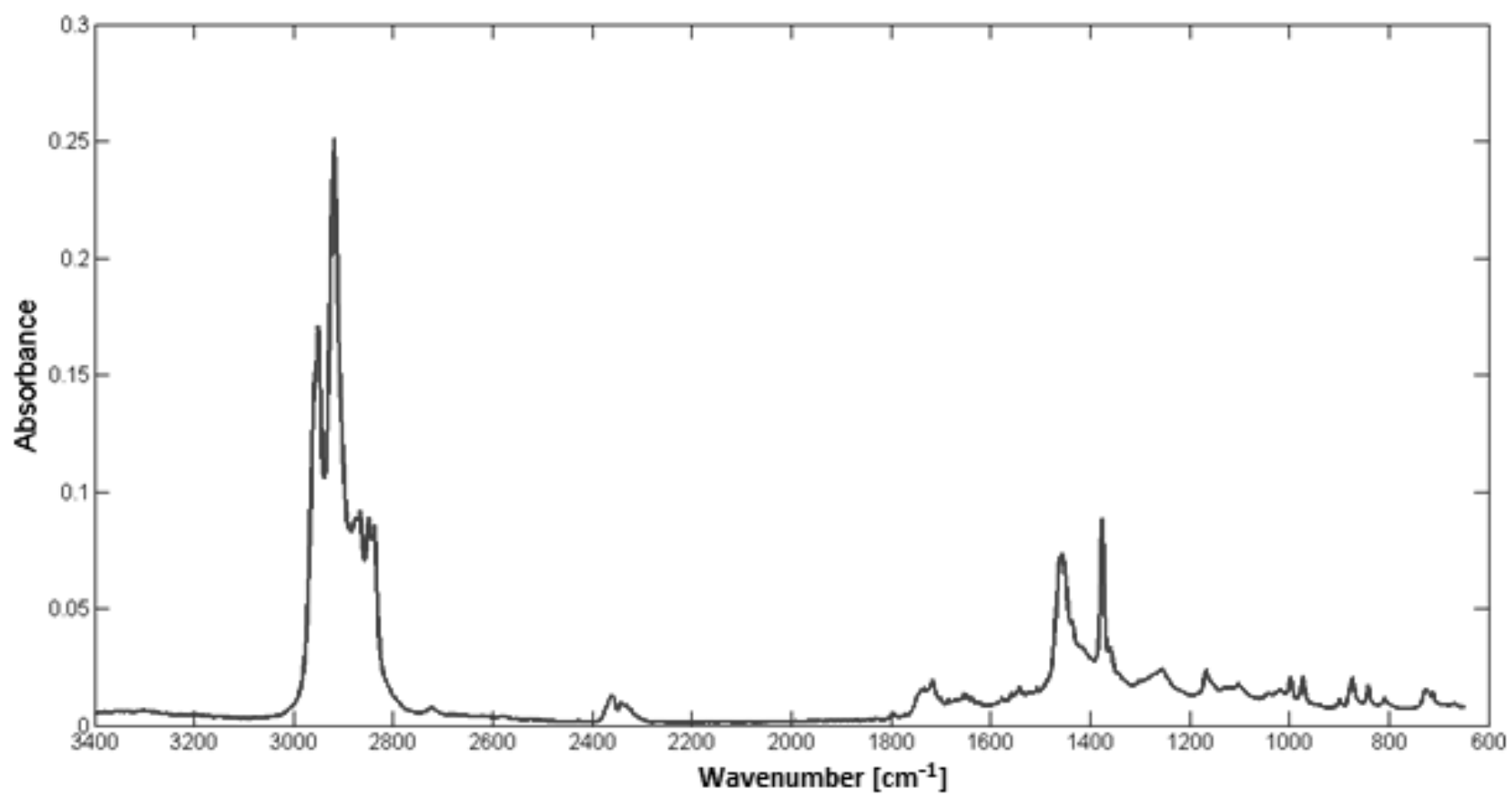

Fig. 4 IR spectrum, sheet sample 


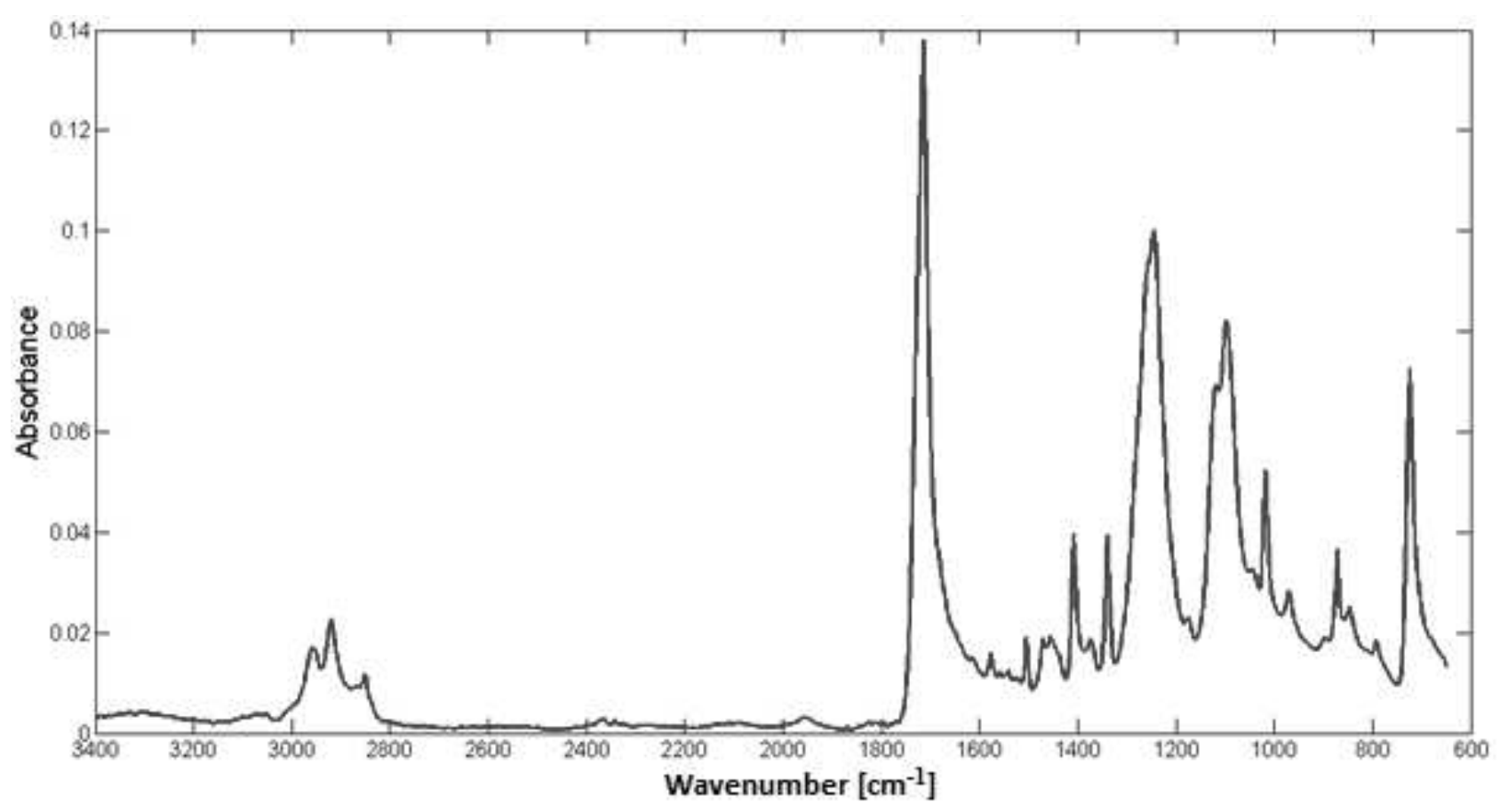

Fig. 5 IR spectrum, fibre sample

Tab.1 Tensile properties at different temperatures

\begin{tabular}{|c|c|c|c|c|}
\hline $\begin{array}{c}\text { Temperature } \\
{\left[{ }^{\circ} \mathrm{C}\right]}\end{array}$ & $\begin{array}{c}\text { Young's modulus } \\
{[\mathrm{MPa}]}\end{array}$ & $\begin{array}{c}\text { Ultimate tensile strength } \\
{[\mathrm{MPa}]}\end{array}$ & $\begin{array}{c}\text { Deformation when UTS rea- } \\
\text { ched [\%] }\end{array}$ & Note \\
\hline 24.2 & $1150 \pm 20$ & $17.0 \pm 0.4$ & $7.9 \pm 0.4$ & $8.2 \pm 0.9$ \\
\hline 39.5 & $1043 \pm 30$ & $15.2 \pm 0.3$ & $8.7 \pm 0.5$ & \\
\hline 60.7 & $649 \pm 11$ & $11.4 \pm 0.4$ & $7.9 \pm 1.8$ & $*$ \\
\hline 80.8 & $397 \pm 35$ & $8.5 \pm 0.3$ & $10.9 \pm 0.8$ & $*$ \\
\hline 100.6 & $256 \pm 8$ & $5.8 \pm 0.2$ & $9.61 \pm 0.6$ & $*$ \\
\hline 121.0 & $175 \pm 9$ & $4.7 \pm 0.3$ & $69.7 \pm 11.4$ & $*$ \\
\hline 141.1 & $96 \pm 8$ & $3.4 \pm 0.3$ & $79.5 \pm 5.7$ & $*$ \\
\hline 160.8 & $60 \pm 7$ & $2.3 \pm 0.1$ & & $*$ \\
\hline
\end{tabular}

(* no breakage)

The results of thermal analysis were evaluated by comparison with material database. The material of the sheet was identified as ethylene-propylene copolymer.

Infrared spectra obtained with FT-IR analysis (Fig. 4 and 5) were evaluated by software comparison with database. Based on the results the material of the sheet was idetified identically to the thermal analysis as ethylenepropylene copolymer. Material of the nonwoven fabric fibers was identified as polyethylene terephthalate (PET).

The tensile properties sumarized in Tab. 1 are very similar to the results obtained by other authors studying ethylene-propylene copolymer [9].

Above $40^{\circ} \mathrm{C}$ the average Young's modulus has decreased by around $35 \%$ and the ultimate tensile strength by around $25 \%$ in every temperature step. Significant increase in elongation was registered above the temperature $120^{\circ} \mathrm{C}$.

Light microscopy observations were carried out in a plane perpendicular to the sheet surface, where both the matrix and the fibers are clearly visible. Results obtained using acrylic resins for the sample mounting (Fig. 6a), were considered unacceptable as the maximum achievable contrast between the resin and the sample is too low. Moreover, the acrylic resin contains tiny cavities which may be confused with the fibers. On the other hand the epoxy resin (Fig. 6b) seems to be a suitable fixing material in which all the components are easily recognizable. Due to its low viscosity in the initial state, the epoxy resin fills all the cracks in the surface as well as the space between the protruding fibers.

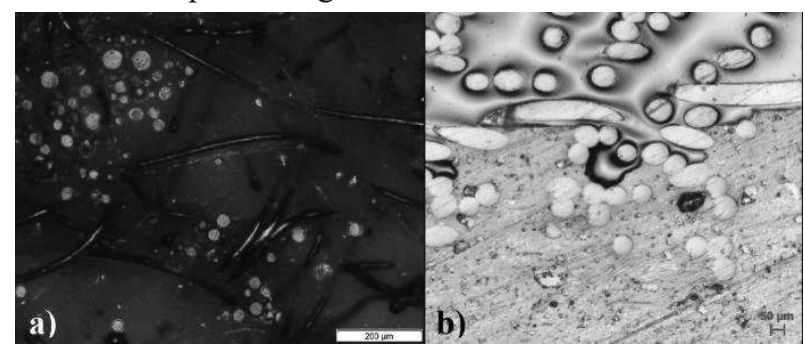

Fig. 6 Mounting resins comparison: a) acrylic resin, b) epoxy resin

The process of sample grinding was optimized gradually to acquire the clearest image possible. Polishing was not beneficial to the final result thus the whole procedure consists only of grinding using diamond discs (Tab. 2). 
Tab. 2 Sample grinding procedure

\begin{tabular}{|c|c|c|c|c|c|}
\hline \multirow{2}{*}{ Disc type } & \multirow{2}{*}{ Granularity } & \multirow{2}{*}{ Time [min] } & \multirow{2}{*}{ Force [N] } & \multicolumn{2}{|c|}{ rpm } \\
\cline { 3 - 4 } Struers MD Piano & 80 & 1 & 30 & & \\
\cline { 2 - 4 } & 220 & 1 & 25 & \multirow{2}{*}{300} & 120 \\
\cline { 2 - 4 } & 500 & 1 & 25 & & \\
\cline { 2 - 4 } & 1200 & individually & 25 & & \\
\hline
\end{tabular}

SEM imaging provided acceptable results when using low vacuum $(30 \mathrm{~Pa})$ in the specimen chamber. This is probably the easiest and the most economical method, since no expensive and time-consuming coating process is needed. Various types of SEM imaging were tested (Fig. 7).
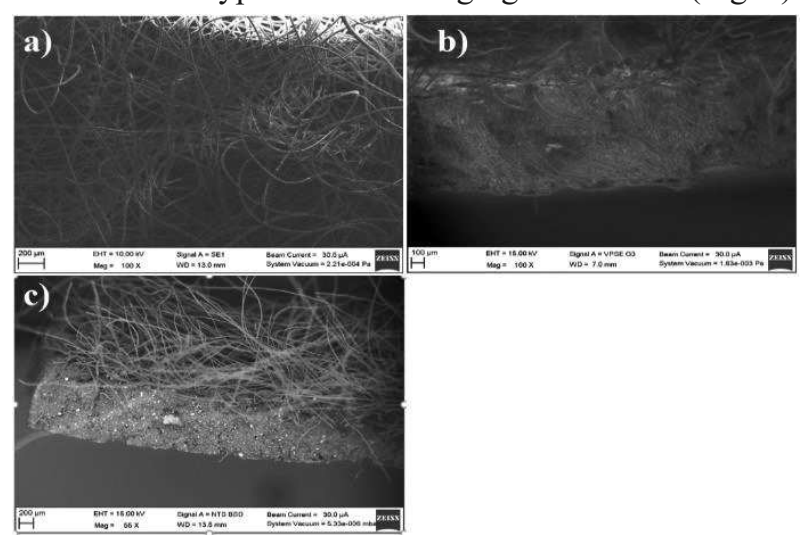

Fig. 7 SEM image (a) high vacuum, secondary electrons, (b) low vacuum, secondary electrons, (c) low vacuum backscattered electrons

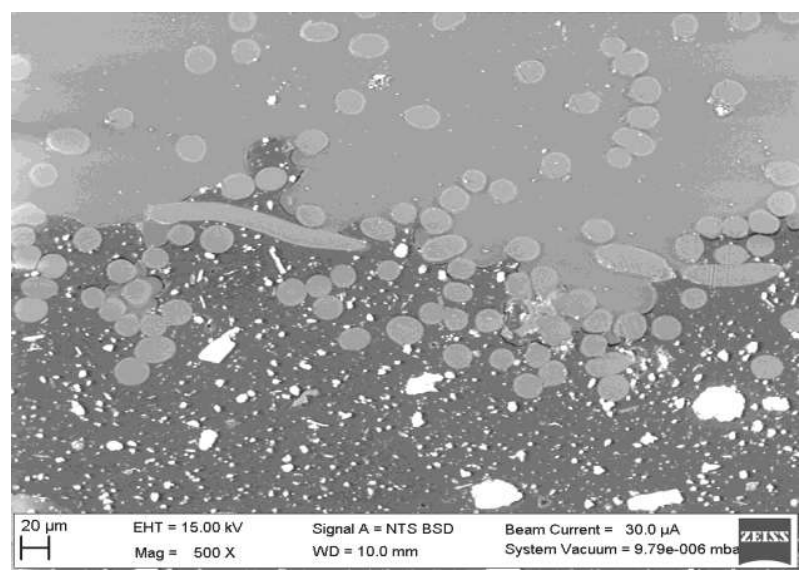

Fig. 8 SEM image, undeformed sample

The use of backscattered electrons signal (Fig. 7c) is obviously the most suitable method both for observing the morphology and detecting the differences in chemical composition. This technique was used to document the samples mounted in epoxy resin as well as fracture surfaces.

SEM observations discovered third phase of the composite - white particles (Fig. 8). Chemical composition of the particles was analysed using energy-dispersive X-ray spectroscopy. The results might be inaccurate due to the low vacuum in the specimen chamber, however significant percentage of calcium $(28.6 \mathrm{wt} \%$ ) was found. Based on the X-ray analysis the white particles were identified as calcium carbonate which is frequently used as filler in polymer materials. The SEM images are suitable for various methods of digital image analysis. Several measurements were performed to determine the average fiber diameter $(20.27 \mu \mathrm{m})$, volume percentage of the filler (15.1 $\%$ ), and maximum Feret diameter of the filler particles (6.64 $\mu \mathrm{m})$.

The changes of deformation mechanism were studied on the deformed samples. At room temperature (Fig. 9), the cracks initiated at the matrix-fiber interface and they propagated perpendicularly to the loading direction. When displayed in the dark field, the crack propagation is more clearly visible (Fig. 9b).

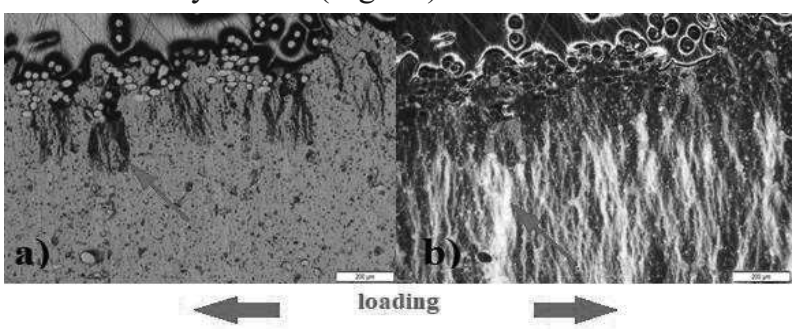

Fig. 9 Tensile specimen deformed at room temperature, (a) bright field, (b) dark field, cracks marked with an arrow

Sample deformed at $140^{\circ} \mathrm{C}$ (Fig. 10) exhibits a different deformation behaviour. The cracks propagated in the loading direction and they were most probably initiated at the matrix - filler particle interface.

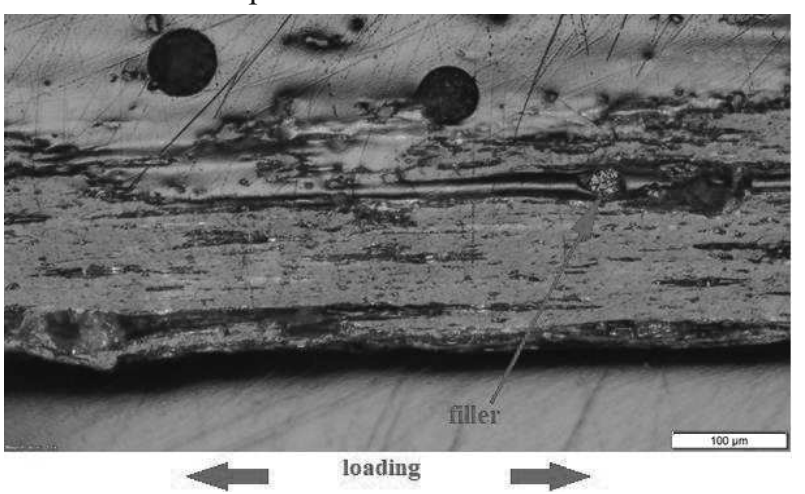

Fig. 10 Tensile specimen deformed at $140^{\circ} \mathrm{C}$

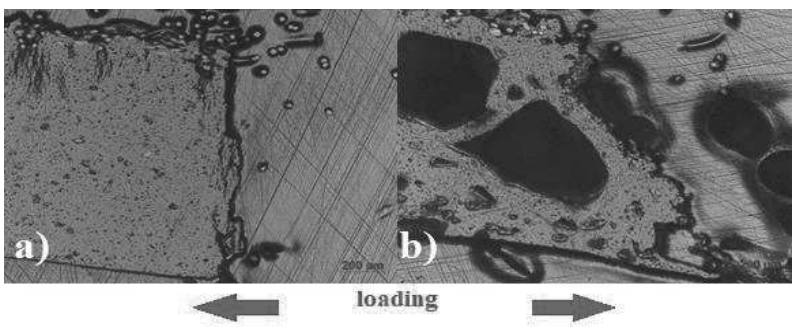

Fig. 11 Side view of fracture, (a) specimen tested at room temperature, (b) specimen tested at $60^{\circ} \mathrm{C}$ 
The fractures exhibit noticeable changes as well. At room temperature (Fig. 11a), the fracture propagated perpendicularly to the loading direction while at $60^{\circ} \mathrm{C}$ (Fig. $11 \mathrm{~b}$ ) it propagated at different angle. In addition, cavities appear close to the fracture surface of the $60^{\circ} \mathrm{C}$ tensile specimen.

SEM imaging (Fig. 12) allows better comparison of the fracture surfaces. Flat fracture surface of the sample tested at $20^{\circ} \mathrm{C}$ (Fig. 12a) indicates brittle behaviour of the material at room temperature. At $60^{\circ} \mathrm{C}$ (Fig. 12b) the sample became very ductile, the surface exhibits no signs of brittle fracture and the cracking takes place in the longitudinal direction.

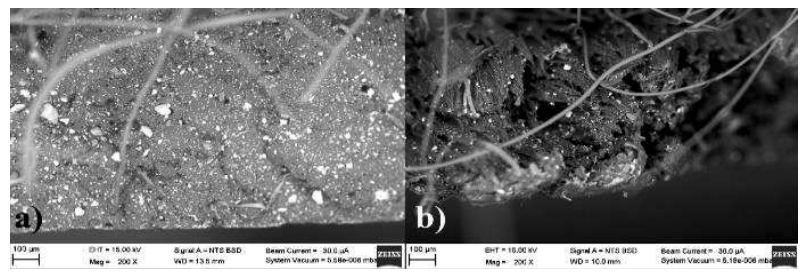

Fig. 12 SEM images of fracture surfaces, (a) specimen tested at room temperature, (b) specimen tested at $60^{\circ} \mathrm{C}$

The samples observed with scanning electron microscope exhibit signs of damage caused by the electron beam (Fig. 13).

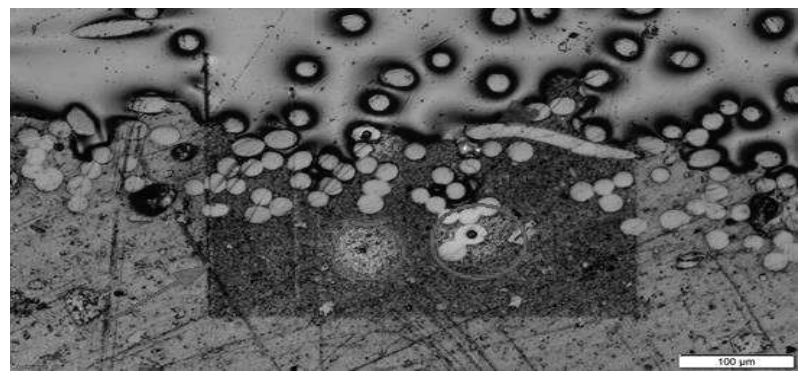

Fig. 13 Sample surface with the rectangular area damaged by electron beam

\section{Conclusion}

In this work a methodology for metallographic evaluation of polymer composites was proposed and subsequently tested on experimental material. The above described procedures have achieved satisfactory results in the image documentation of mounted samples and fracture surfaces. The acquired images were subjected to digital image analysis (phase percentage measurement, particle size measurement). In addition, temperature dependent changes in deformation mechanism of the tensile specimens were observed.

Methods of thermal analysis and infrared spectroscopy were employed successfully to indentify both main phases of the composite.

Mechanical properties (tensile strength, modulus) were obtained by tensile testing at various temperatures from $20^{\circ} \mathrm{C}$ to $160^{\circ} \mathrm{C}$. The temperature dependence of deformation mechanism of the tensile samples was observed with light microscope and SEM. These observations might be useful for further research in order do find suitable processing temperature and deformation for this material.

As a starting point for further research, optimization of electron microscopic observation parameters is considered to reduce or prevent the damage to the sample by the electron beam.

\section{Acknowledgement}

The present contribution has been prepared under project LO1502 'Development of the Regional Technological Institute' under the auspices of the National Sustainability Programme I of the Ministry of Education of the Czech Republic aimed to support research, experimental development and innovation.

\section{References}

[1] JANČÁ̌̆, J. (2003). Úvod do materiálového inženýrství polymernich kompozitů (Introdiction to material engineering of polymer composites). Vysoké učení technické v Brně, Fakulta chemická, ISBN: 80-214-2443-5, Brno.

[2] EHRENSTEIN, G. W. (2006). Polymerní kompozitni materiály (Polymer composite materials). Scientia,. ISBN 978-80-86960-29-6, .

[3] RÁŽ, K., et al (2017). Analysis of Weld Line Influence on Strength of Nylon Parts. In: Manufacturing Technology. Vol. 17, No. 4, pp. 561-565. ISSN 1213-2489.

[4] KALOVA, M., RUSNAKOVA, S. (2017). Microstructure of Polymer Composite Materials. In: Manuacturing Technology, Vol 17, No. 5, 5, pp.722-728. ISSN 1213-2489.

[5] JANOVEC, J., CEJPL, J., STEIDL, J. (2008). Perspektivni materiály (Promising materials). České vysoké učení technické v Praze, Praha.

[6] ZADRAŽIL, M. (2002). Zobrazování nevodivých praparátů metodou nenabijeci elektronové mikroskopie (Imaging of non-conductive samples with charging electron microscopy). Vysoké učení technické v Brně. ISBN 80-214-2139-8, Brno.

[7] KUBÍNEK, R., ŠAFÁŘOVÁ, K., VŮJTEK, M. (2011). Elektronová mikroskopie (Electron microscopy). Univerzita Palackého v Olomouci. ISBN 978-80-244-2739-3, Olomouc.

[8] NOVOTNÝ, J., JASKEVIČ, M. a LYSOŇKOVÁ , I. (2018). Mesocomposites Based on the Polymethylmethacrylate Matrix. In: Manufacturing technology. Vol. 18, No. 5, pp. 799-804. ISSN 12132489.

[9] GOMEZ DEL RÍO, T., SALAZAR, A. A RODRÍGUEZ, J. (2012) Effect of strain rate and temperature on tensile properties of ethylene-propylene block copolymers. In: Materials and Design, Vol. 42, No. 1, pp. 301-307. Elsevier Ltd. 